\title{
Treatment of osteonecrosis of the jaw related to bisphosphonates and other antiresorptive agents
}

\author{
Francisco-Javier Rodriguez-Lozano ${ }^{1}$, Ricardo-Elías Oñate-Sánchez ${ }^{2}$
}

${ }^{1}$ DDS, PhD, Assistant Lecturer. Special Patients and Gerodontology Unit. School of Dentistry, University of Murcia, IMIBArrixaca, Spain

${ }^{2}$ MD, DDS, PhD, Senior Lecturer. Special Patients and Gerodontology Unit. School of Dentistry, University of Murcia, IMIBArrixaca, Spain

Correspondence:

Clínica Odontológica Universitaria

Unidad Pacientes Especiales y Gerodontología

University of Murcia

IMIB-Arrixaca. Morales Meseguer Hospital

Avda. Marqués de los Vélez s/n

30007- Murcia, Spain

fcojavier@um.es

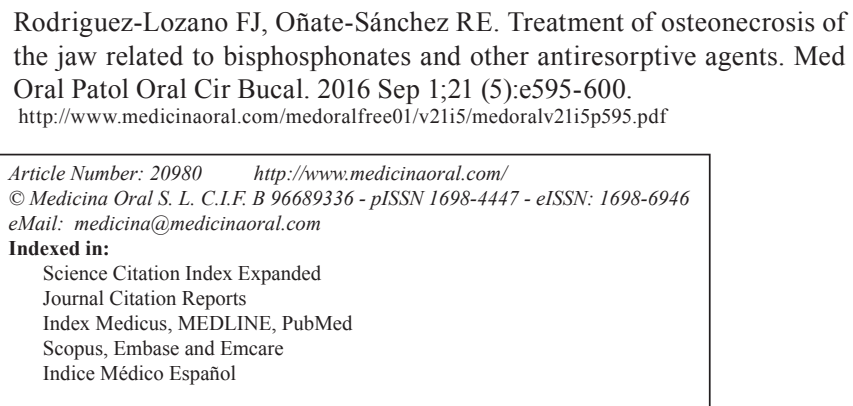

\begin{abstract}
Background: The clinical management of medication-related osteonecrosis of the jaw (MRONJ) in patients treated with bisphosphonates and other antiresorptive agents is subject to controversy. The American Association of Oral and Maxillofacial Surgeons (AAOMS) has developed guidelines for the correct management of the disorder which are revised and updated by a panel of experts.

Material and Methods: The present systematic review analyzes the different treatments currently used to treat this clinical condition, based on the PRISMA® (Preferred Reporting Items for Systematic Reviews and MetaAnalyses) statement published in 2009. An electronic Medline search was made of the PubMed database, covering the period 2006-2014. The last search date was 31 December 2014.

Results: A total of 29 articles were selected from the initial search according to the different drugs implicated in the appearance of osteonecrosis; the treatment modality used according to the stage of the disease; and the recorded success rate.

Conclusions: It is currently still recommended that the management of MRONJ should be decided according to the stage of the disease - conservative treatment being preferred in early stages without symptoms, while surgical management is preferred in the case of bone exposure with symptoms.
\end{abstract}

Key words: Osteonecrosis, medication, bisphosphonates, treatments, review. 


\section{Introduction}

The American Association of Oral and Maxillofacial Surgeons (AAOMS) has recently suggested changing the term "bisphosphonate-related osteonecrosis of the jaw (BRONJ)" to "medication-related osteonecrosis of the jaw (MRONJ)", in view of the increase in frequency of maxillary and mandibular osteonecrosis related not only to bisphosphonates (BPs) but also to other antiresorptive agents such as denosumab and antiangiogenic drugs (1). The AAOMS position document has also modified the definition of MRONJ established in 2009 (2), and patients susceptible to MRONJ are now defined as those presenting the following characteristics: a) a history of antiresorptive or antiangiogenic drug treatment; b) the presence of bone exposure or intra- or extraoral fistulization for over 8 weeks without remission; and c) no history of radiotherapy or diseases metastasizing to the maxilla.

However, osteonecrosis of the jaw associated to these drugs has been the subject of controversy ever since the first case was reported in 2003 (3). The AAOMS considers prevention to be the key element in dealing with MRONJ. In this regard, a multidisciplinary team in which the dentist plays a fundamental role is required to define management of the lesions. Consultation of the dentist before starting antiresorptive or antiangiogenic drug treatment considerably reduces the risk of developing MRONJ in the event of osteonecrosis-triggering interventions such as tooth extractions (4-6).

Many authors have studied the management of MRONJ, including different treatments such as surgical debridement, resection of the lesions, oxygen therapy and recently also the use of mesenchymal cells to regenerate the damaged bone (7-9). The type of treatment depends on the diagnosis and clinical stage of MRONJ. A staging system was developed in 2006 by Ruggiero et al. (10), and was subsequently adopted by the AAOMS with updates in 2007, 2009 and 2014 (1,2,11).

Independently of the stage of the disease, initial treatment must seek to control the pain and bone infection / necrosis, in order to preserve patient quality of life (1). Despite the current recommendations of the AAOMS advocating conservative management of MRONJ, a number of studies have found this approach to be successful in only $20 \%$ of the cases, versus in over $85 \%$ when surgical treatment is decided (12).

The present study offers a systematic review of the different treatments currently used in application to MRONJ reflected in the literature, based on the stage of the disease, and examines the results of each treatment modality according to the associated success rates.

\section{Material and Methods}

The present systematic review was based on the PRISMA® (Preferred Reporting Items for Systematic Re- views and Meta-Analyses) statement published in 2009 (13). An electronic Medline search was made of the PubMed database, covering the period 2006-2014. The last search date was 31 December 2014. The identified references were processed using Endnote ${ }^{\circledR}$.

Framing the question (PICO): What are the treatments used for medication-related osteonecrosis of the jaw and their success rates?

- Search strategy:

The literature search was made using the following key words: "medication", "bisphosphonates", "antiresorptive", "antiangiogenic", "denosumab", "sunitinib", "osteonecrosis", "jaw" and "treatment", combined with the boolean operators AND / OR. The electronic search was complemented by a manual search of the references found in the manuscripts and involving the following journals: British Journal of Oral and Maxillofacial Surgery, International Journal of Oral and Maxillofacial Surgery, Journal of Oral and Maxillofacial Surgery, Oral Oncology, Oral Surgery, Oral Medicine, Oral Pathology, Oral Radiology and Endodontology, Journal of Periodontology, Medicina Oral, Patología Oral y Cirugía Bucal. After eliminating duplications, the potential titles and abstracts were filtered based on the following criteria:

- Inclusion criteria:

Articles entirely in English, referred to medication-related osteonecrosis of the jaw (bisphosphonates, antiresorptive agents and antiangiogenic drugs) in humans, and without sample limitations.

- Exclusion criteria:

Publications in languages other than English, systematic reviews, experimental studies in animals, and letters to the Editor.

All the information was compiled from the selected articles by a single reviewer (FJRL). The documented variables included general data such as the author, country, year of publication, objectives, patient characteristics, and information referred to interventions and follow-up. The specific study variables included clinical response indicators such as disappearance of the lesions, recurrence or evolution of the disease, and the frequency and severity of adverse reactions for the assessment of safety.

\section{Results and Discussion}

The systematic PubMed search adopting the search strategy: (medication) AND osteonecrosis) AND jaw) AND treatment) AND (“2006/01/01” [Date - Publication] : "2014/12/31" [Date - Publication]) yielded a total of 85 articles. After reading the title and abstract, 74 of the articles that failed to meet the inclusion criteria were excluded from the study. The search strategy: (bisphosphonates) AND osteonecrosis) AND treatment) AND ("2006/01/01" [Date - Publication]: "2014/12/31” [Date 
- Publication]) AND jaw yielded 1151 articles, of which 15 meeting the inclusion criteria were included in the study. Lastly, the search strategy: (denosumab) AND osteonecrosis) AND treatment) AND ("2006/01/01" [Date-Publication]: “2014/12/31” [Date-Publication]) AND jaw yielded 74 articles, of which three meeting the inclusion criteria were included in the study.

Following the electronic search and selection of the publications that met the established inclusion criteria, a total of 29 articles were selected (Fig. 1). A brief description of these studies is provided below, together with a summary of the different treatment options currently used in application to medication-related osteonecrosis of the jaw (MRONJ).

a) Conservative management

Patients amenable to conservative management would be those considered to be at risk and/or individuals without symptoms (stage I) (1). We could also include patients who for health reasons are not candidates for surgical treatment, or who are receiving cancer treatment. Due to the intrinsic definition of MRONJ, which implies "exposed bone", surgery in principle would be the treatment option of choice - though some authors consider that conservative management can improve or keep the disease asymptomatic in up to $70 \%$ of the cases. Nevertheless, this favorable percentage cannot be regarded as representing treatment success, though temporary patient relief is provided (14). Conservative management includes the reinforcement of oral hygiene, periodic dental checks, oral rinses with chlorhexidine, and antibiotic treatment. In this regard, the most widely used antibiotics are amoxicillin with or without clavulanic acid (500 mg/1 g) clindamycin (300 mg), azithromycin $(500 \mathrm{mg})$ and in some cases the combination of metronidazole with betalactams. In most of the studies, this approach resulted in the stabilization of osteonecrosis or simply the improvement of symptoms $(14,15)$. In fact, higher success rates are only achieved when such treatments are combined with other conservative measures such as ozone therapy, hyperbaric oxygen and low-power laser therapy - though the rates are not comparable to those obtained with surgery (16).

Ozone therapy stimulates cell proliferation and soft tissue healing, and reduces pain, with promising results in phase I/II clinical trials. As such, this treatment modality could constitute a new alternative in the management of MRONJ (17). Hyperbaric oxygen (HBO) has sometimes been used in application to MRONJ, with controversial results. Historically, the healing action of HBO has been attributed to the creation of beneficial oxygen

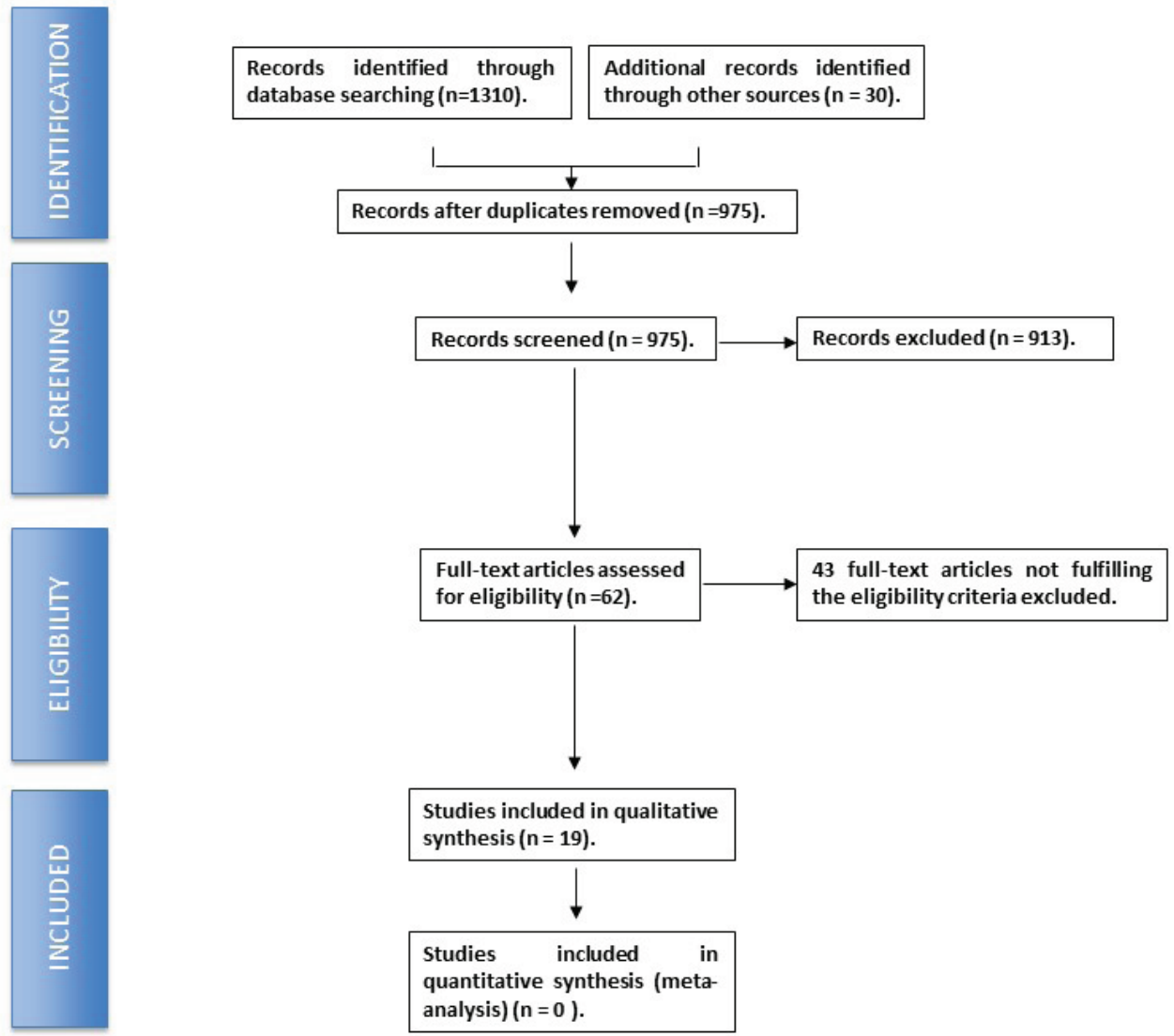

Fig. 1. PRISMA® flowchart describing the search strategy and inclusion of the studied articles. 
gradients. The reason for using $\mathrm{HBO}$ in MRONJ is that different authors consider it to improve wound healing, reduce edema and swelling, stimulate stem cell mobilization, and moderate the bone turnover suppression caused by bisphosphonates $(16,18)$. Low-intensity laser therapy (LILT) has been shown to be an innovating and effective treatment in medicine, with effects that include the lessening of pain, improved wound healing, and the facilitation of nerve regeneration. It also exerts antimicrobial effects and facilitates the healing of wounds in the oral cavity, including the stimulation of reepithelization after periodontal or third molar surgery. Different studies have warranted the use of LILT on the basis of its biostimulating effects in MRONJ lesions $(16,19)$.

Pentoxifylline and $\alpha$-tocopherol have been suggested to assist antimicrobial therapy in the early stages of MRONJ, since these substances have been found to reduce the bone exposure area and symptoms in $74 \%$ of the cases $(16,20)$. Table 1 summarizes the studies made using conservative treatments in MRONJ, with the associated success rates (21-23).

a) Surgical management, alone or in combination with other treatments

There is general agreement on the advisability of surgery in those cases characterized by chronic exposure of necrotic bone, since the latter can interfere with wound healing and is of course infected (24). In these cases, minimum necessary necrotic bone elimination is indicated, and two surgical approaches have been recommended in this respect: (i) conservative debridement or surgery; and (ii) segmental resection. This latter approach applies to stage II/III MRONJ and cases in which nonsurgical conservative management has failed (24) (Table 2).

i.) Conservative surgery

Conservative surgery involves the removal of dead bone

Table 1. Summary of studies involving a conservative approach to the management of medication-related osteonecrosis of the jaw. (MRONJ).

\begin{tabular}{|c|c|c|}
\hline TYPE OF TREATMENT & AUTHOR / YEAR & $\begin{array}{c}\text { No. PATIENTS HEALED / No. } \\
\text { PATIENTS TREATED (\%) }\end{array}$ \\
\hline \multirow{4}{*}{ Antibiotic treatment } & Melea et al. (2014) (15) & $23 / 38(60 \%)$ \\
\hline & Van den Wyngaert et al. (2009) (21) & $16 / 33(53 \%)$ \\
\hline & Scoletta et al. (2010) (22) & $18 / 30(62 \%)$ \\
\hline & Nicolatou-Galitis et al. (2011) (23) & $7 / 47(14.9 \%)$ \\
\hline T Antibiotic treatment + hyperbaric oxygen & Freiberger et al. (2012) (18) & $13 / 25(52 \%)$ \\
\hline Antibiotic treatment + ozone therapy & Ripamonti et al. (2011) (17) & $10 / 10(100 \%)$ \\
\hline Pentoxifylline $+\alpha$-tocopherol & Magremanne et al. (2014) (20) & $1 / 1(100 \%)$ \\
\hline
\end{tabular}

Table 2. Summary of studies involving a surgical approach to the management of medication-related osteonecrosis of the jaw (MRONJ). L-PRF (Leukocyte- and platelet-rich fibrin mesh).

\begin{tabular}{|c|c|c|}
\hline TYPE OF TREATMENT & AUTHOR / YEAR & $\begin{array}{l}\text { No. PATIENTS HEALED / No. } \\
\text { PATIENTS TREATED (\%) }\end{array}$ \\
\hline CONSERVATIVE SURGERY & $\begin{array}{l}\text { Rugani et al. } 2014 \text { (24) } \\
\text { Vescovi et al. (2012) (28) } \\
\text { Thumbigere-Math et al. (2009) (30) } \\
\text { Williamson et al. (2010) et al. (25) } \\
\text { Vescovi et al. (2014) (16) } \\
\text { Graziani et al. (2012) (26) } \\
\text { Wutzl et al. (2008) (27) }\end{array}$ & $\begin{array}{c}15 / 17(88.2 \%) \\
11 / 17(65 \%) \\
3 / 19(15 \%) \\
40 / 40(100 \%) \\
25 / 27(92.6 \%) \\
227(54 \%) \\
24 / 41(59 \%)\end{array}$ \\
\hline $\begin{array}{l}\text { CONSERVATIVE SURGERY } \\
+ \text { OZONE THERAPY }\end{array}$ & Agrillo et al. (35) & $57 / 94(60 \%)$ \\
\hline $\begin{array}{l}\text { CONSERVATIVE } \text { SURGERY } \\
+ \text { L-PRF }\end{array}$ & Kim et al. (41) & $26 / 34(77 \%)$ \\
\hline RESECTIVE SURGERY & $\begin{array}{l}\text { Graziani et al. (2012) (26) } \\
\text { Carlson and Basile (2009) (34) } \\
\text { Bedogni et al. (2011) (31) } \\
\text { Voss et al. (2012) (32) } \\
\text { Schubert et al. (2012) (33) }\end{array}$ & $\begin{array}{c}87 / 120(72.5 \%) \\
87 / 95(92 \%) \\
27 / 30(90 \%) \\
20 / 21(95 \%) \\
47 / 54(87 \%)\end{array}$ \\
\hline
\end{tabular}


(sequestrectomy) and/or superficial surgical debridement of necrotic bone associated to oral antibiotics and chlorhexidine rinses. Most authors recommend scantly invasive surgery for MRONJ, since according to the reviewed literature this approach affords healing rates of over 50\% (16,25-27). Wutzl et al. (27) carried out the first prospective study evaluating the outcome of surgery after 6 months in a cohort of 58 patients with osteonecrosis of the jaw. They found $58.5 \%$ of the patients to be free of pain and with an intact oral mucosa. Eleven out of 12 patients subjected to flap procedures for soft tissue closure presented a healthy mucosa. The authors showed that minimal resection of the necrotic bone and local soft tissue closure can afford satisfactory results. Complementary treatments added to surgery have also been described in the literature. Vescovi et al. (28) obtained good results in MRONJ by combining surgical debridement with laser therapy. However, Atalay et al. (19) observed no statistically significant benefits with this approach compared with conventional surgery. Martins et al. (29) conducted a study in patients treated with antibiotics plus surgery, followed by low-intensity laser therapy and platelet-rich plasma applied to the surgical wound. The healing rates were found to be higher than in the patients subjected only to surgery and antibiotic treatment. In contrast, other investigators such as Thumbigere-Math et al. recorded a success rate of only $15 \%$ and observed colonization by Actinomyces spp. in those cases with exposed bone (30).

ii) Resective or extensive (segmental) surgery

In those patients in which previous treatment has failed, or in very advanced cases of MRONJ, resective or extensive (segmental) surgery is indicated with the purpose of eliminating all the necrotic tissue, leaving only healthy bone. However, resective surgery has generated controversy, since in many cases it is difficult to eliminate all the necrotic bone and guarantee the obtainment of healthy bone margins (31-33). Carlson and Basile (34) reported a very high success rate $(92 \%)$ in MRONJ patients subjected to mandibular segmental resection and partial maxillectomy with the purpose of securing clean margins with healthy bone. However, disinfection measures associated to the surgical procedure are needed - hence the combination of surgery with other therapies such as ozone (35), laser irradiation (16) and, in particular, prolonged antibiotic treatment (generally penicillin, or tetracycline or clindamycin in patients allergic to penicillin) (36). Additional measures such as the use of stem cells (9,37), platelet-rich plasma (38), the administration of parathyroid hormone $(39,40)$, or the use of leukocyte and platelet-rich fibrin meshes (41) are also promising strategies - though further clinical studies are needed in order to confirm their efficacy / effectiveness.

\section{Conclusions}

It is currently still recommended that the management of MRONJ should be decided according to the stage of the disease - conservative treatment being preferred in early stages without symptoms, while surgical management is preferred in the case of bone exposure with symptoms. Effective and scantly invasive alternatives affording good patient quality of life will be the future treatments of choice, though at present there is no agreement as to which management approach is best suited to each specific circumstance.

\section{References}

1. Ruggiero SL, Dodson TB, Fantasia J, Goodday R, Aghaloo T, Mehrotra B, et al. American Association of Oral and Maxillofacial Surgeons Position Paper on Medication-Related Osteonecrosis of the Jaw-2014 Update. J Oral Maxillofac Surg. 2014;72:1938-56.

2. Ruggiero SL, Dodson TB, Assael LA, Landesberg R, Marx RE, Mehrotra B. American Association of Oral and Maxillofacial Surgeons Position Paper on Bisphosphonate-Related Osteonecrosis of the Jaws-2009 Update. Journal of Oral and Maxillofacial Surgery. 2009;67:2-12.

3. Marx RE. Pamidronate (Aredia) and zoledronate (Zometa) induced avascular necrosis of the jaws: a growing epidemic. J Oral Maxillofac Surg. 2003;61:1115-7.

4. Ripamonti CI, Maniezzo M, Campa T, Fagnoni E, Brunelli C, Saibene G, et al. Decreased occurrence of osteonecrosis of the jaw after implementation of dental preventive measures in solid tumour patients with bone metastases treated with bisphosphonates. The experience of the National Cancer Institute of Milan. Ann Oncol. 2009;20:137-45.

5. Dimopoulos MA, Kastritis E, Bamia C, Melakopoulos I, Gika D, Roussou M, et al. Reduction of osteonecrosis of the jaw (ONJ) after implementation of preventive measures in patients with multiple myeloma treated with zoledronic acid. Ann Oncol. 2009;20:117-20.

6. Bagan JV, Jimenez Y, Murillo J, Hernandez S, Poveda R, Sanchis JM, et al. Jaw osteonecrosis associated with bisphosphonates: multiple exposed areas and its relationship to teeth extractions. Study of 20 cases. Oral Oncol. 2006;42:327-9.

7. Rupel K, Ottaviani G, Gobbo M, Contardo L, Tirelli G, Vescovi $\mathrm{P}$, et al. A systematic review of therapeutical approaches in bisphosphonates-related osteonecrosis of the jaw (BRONJ). Oral Oncol. 2014;50:1049-57.

8. Ruggiero SL, Mehrotra B, Rosenberg TJ, Engroff SL. Osteonecrosis of the jaws associated with the use of bisphosphonates: a review of 63 cases. J Oral Maxillofac Surg. 2004;62:527-34.

9. Gonzálvez-García M, Rodríguez-Lozano FJ, Villanueva V, Segarra-Fenoll D, Rodríguez-González MA, Oñate-Sánchez R, et al. Cell therapy in bisphosphonate-related osteonecrosis of the jaw. J Craniofac Surg. 2013;24:e226-8.

10. Ruggiero SL, Fantasia J, Carlson E. Bisphosphonate-related osteonecrosis of the jaw: background and guidelines for diagnosis, staging and management. Oral Surg Oral Med Oral Pathol Oral Radiol Endod. 2006;102:433-41.

11. Ruggiero SL. Guidelines for the diagnosis of bisphosphonaterelated osteonecrosis of the jaw (BRONJ). Clin Cases Miner Bone Metab. 2007;4:37-42.

12. Ristow O, Otto S, Troeltzsch M, Hohlweg-Majert B, Pautke C. Treatment perspectives for medication-related osteonecrosis of the jaw (MRONJ). J Craniomaxillofac Surg. 2015;43:290-3.

13. Liberati A, Altman DG, Tetzlaff J, Mulrow C, Gøtzsche PC, Ioannidis JP, et al. The PRISMA statement for reporting systematic reviews and meta-analyses of studies that evaluate health care interventions: explanation and elaboration. J Clin Epidemiol. 2009;62:e134. 
14. Lerman MA, Xie W, Treister NS, Richardson PG, Weller EA, Woo SB. Conservative management of bisphosphonate-related osteonecrosis of the jaws: staging and treatment outcomes. Oral Oncol. 2013;49:977-83.

15. Melea PI, Melakopoulos I, Kastritis E, Tesseromatis C, Margaritis V, Dimopoulos MA, et al. Conservative treatment of bisphosphonate-related osteonecrosis of the jaw in multiple myeloma patients. Int J Dent. 2014;2014:427273.

16. Vescovi P, Merigo E, Meleti M, Manfredi M, Fornaini C, Nammour $\mathrm{S}$, et al. Conservative surgical management of stage I bisphosphonate-related osteonecrosis of the jaw. Int J Dent. 2014;2014:107690. 17. Ripamonti CI, Cislaghi E, Mariani L, Maniezzo M. Efficacy and safety of medical ozone (O (3)) delivered in oil suspension applications for the treatment of osteonecrosis of the jaw in patients with bone metastases treated with bisphosphonates: Preliminary results of a phase I-II study. Oral Oncol. 2011;47:185-90.

18. Freiberger JJ, Padilla-Burgos R, McGraw T, Suliman HB, Kraft $\mathrm{KH}$, Stolp BW, et al. What is the role of hyperbaric oxygen in the management of bisphosphonate-related osteonecrosis of the jaw: a randomized controlled trial of hyperbaric oxygen as an adjunct to surgery and antibiotics. J Oral Maxillofac Surg. 2012;70:1573-83.

19. Atalay B, Yalcin S, Emes Y, Aktas I, Aybar B, Issever H, et al. Bisphosphonate-related osteonecrosis: laser-assisted surgical treatment or conventional surgery?. Lasers Med Sci. 2011;26:815-23.

20. Magremanne M, Reychler H. Pentoxifylline and tocopherol in the treatment of yearly zoledronic acid-related osteonecrosis of the jaw in a corticosteroid-induced osteoporosis. J Oral Maxillofac Surg. 2014;72:334-7.

21. Van den Wyngaert T, Claeys T, Huizing MT, Vermorken JB, Fossion E. Initial experience with conservative treatment in cancer patients with osteonecrosis of the jaw (ONJ) and predictors of outcome. Ann Oncol. 2009;20:331-6.

22. Scoletta M, Arduino PG, Dalmasso P, Broccoletti R, Mozzati M. Treatment outcomes in patients with bisphosphonate-related osteonecrosis of the jaws: a prospective study. Oral Surg Oral Med Oral Pathol Oral Radiol Endod. 2010;110:46-53.

23. Nicolatou-Galitis O, Papadopoulou E, Sarri T, Boziari P, Karayianni A, Kyrtsonis MC, et al. Osteonecrosis of the jaw in oncology patients treated with bisphosphonates: prospective experience of a dental oncology referral center. Oral Surg Oral Med Oral Pathol Oral Radiol Endod. 2011;112:195-202.

24. Rugani P, Acham S, Kirnbauer B, Truschnegg A, ObermayerPietsch B, Jakse N. Stage-related treatment concept of medicationrelated osteonecrosis of the jaw-a case series. Clin Oral Investig. 2015;19:1329-38.

25. Williamson RA. Surgical management of bisphosphonate induced osteonecrosis of the jaws. Int J Oral Maxillofac Surg. 2010;39:251-5. 26. Graziani F, Vescovi P, Campisi G, Favia G, Gabriele M, Gaeta $\mathrm{GM}$, et al. Resective surgical approach shows a high performance in the management of advanced cases of bisphosphonate-related osteonecrosis of the jaws: a retrospective survey of 347 cases. J Oral Maxillofac Surg. 2012;70:2501-7.

27. Wutzl A, Biedermann E, Wanschitz F, Seemann R, Klug C, Baumann A, et al. Treatment results of bisphosphonate-related osteonecrosis of the jaws. Head Neck. 2008;30:1224-30.

28. Vescovi P, Merigo E, Meleti M, Manfredi M, Guidotti R, Nammour S. Bisphosphonates-related osteonecrosis of the jaws: a concise review of the literature and a report of a single-centre experience with 151 patients. J Oral Pathol Med. 2012;41:214-21.

29. Martins MA, Martins MD, Lascala CA, Curi MM, Migliorati CA, Tenis CA, et al. Association of laser phototherapy with PRP improves healing of bisphosphonate-related osteonecrosis of the jaws in cancer patients: a preliminary study. Oral Oncol. 2012;48:79-84.

30. Thumbigere-Math V, Sabino MC, Gopalakrishnan R, Huckabay S, Dudek AZ, Basu S, et al. Bisphosphonate-related osteonecrosis of the jaw: clinical features, risk factors, management, and treatment outcomes of 26 patients. J Oral Maxillofac Surg. 2009;67:1904-13.
31. Bedogni A, Saia G, Bettini G, Tronchet A, Totola A, Bedogni G, et al. Long-term outcomes of surgical resection of the jaws in cancer patients with bisphosphonate-related osteonecrosis. Oral Oncol. 2011;47:420-4.

32. Voss PJ, Joshi Oshero J, Kovalova-Müller A, Veigel Merino EA, Sauerbier S, Al-Jamali J, et al. Surgical treatment of bisphosphonateassociated osteonecrosis of the jaw: technical report and follow up of 21 patients. J Craniomaxillofac Surg. 2012;40:719-25.

33. Schubert M, Klatte I, Linek W, Müller B, Döring K, Eckelt U, et al. The saxon bisphosphonate register - therapy and prevention of bisphosphonate-related osteonecrosis of the jaws. Oral Oncol. 2012;48:349-54.

34. Carlson ER, Basile JD. The role of surgical resection in the management of bisphosphonate-related osteonecrosis of the jaws. J Oral Maxillofac Surg. 2009;67:85-95.

35. Agrillo A, Filiaci F, Ramieri V, Riccardi E, Quarato D, Rinna C, et al. Bisphosphonate-related osteonecrosis of the jaw (BRONJ): 5 year experience in the treatment of 131 cases with ozone therapy. Eur Rev Med Pharmacol Sci. 2012;16:1741-7.

36. Montefusco V, Gay F, Spina F, Miceli R, Maniezzo M, Teresa Ambrosini M, et al. Antibiotic prophylaxis before dental procedures may reduce the incidence of osteonecrosis of the jaw in patients with multiple myeloma treated with bisphosphonates. Leuk Lymphoma. 2008;49:2156-62.

37. Cella L, Oppici A, Arbasi M, Moretto M, Piepoli M, Vallisa D, et al. Autologous bone marrow stem cell intralesional transplantation repairing bisphosphonate related osteonecrosis of the jaw. Head Face Med. 2011;7:16.

38. Curi MM, Cossolin GS, Koga DH, Zardetto C, Christianini S, Feher O, et al. Bisphosphonate-related osteonecrosis of the jaws--an initial case series report of treatment combining partial bone resection and autologous platelet-rich plasma. J Oral Maxillofac Surg. 2011;69:2465-72.

39. Cheung A, Seeman E. Teriparatide therapy for alendronate-associated osteonecrosis of the jaw. N Engl J Med. 2010;363:2473-4. 40. Neuprez A, Rompen E, Crielaard JM, Reginster JY. Teriparatide therapy for denosumab-induced osteonecrosis of the jaw in a male osteoporotic patient. Calcif Tissue Int. 2014;95:94-6.

41. Kim JW, Kim SJ, Kim MR. Leucocyte-rich and platelet-rich fibrin for the treatment of bisphosphonate-related osteonecrosis of the jaw: a prospective feasibility study. Br J Oral Maxillofac Surg. 2014;52:854-9.

\section{Acknowledgments}

This work was supported by FIS EC07/90762 Grant and the Spanish Net of Cell Therapy (TerCel) provided by Carlos III Institute of Health (ISCiii) (PI13/02699 and EC11-009) together with the Foundation Robles Chillida (PI/2015) .

Conflict of Interest

The authors have declared that no conflict of interest exist. 